\title{
Learning spaces and pedagogic change: envisioned, enacted and experienced
}

\author{
Dianne Mulcahy $^{\mathrm{a}}$, Ben Cleveland ${ }^{\mathrm{b}}$ and Helen Aberton ${ }^{\mathrm{a}}$ \\ ${ }^{a}$ Melbourne Graduate School of Education, University of Melbourne, Melbourne, \\ Victoria, Australia; ${ }^{b}$ Faculty of Architecture, Building and Planning, University of \\ Melbourne, Melbourne, Victoria, Australia
}

\begin{abstract}
Building on work in how spaces of learning can contribute to the broader policy agenda of achieving pedagogic change, this article takes as its context the Building the Education Revolution infrastructure programme in Australia. Deploying a sociomaterial approach to researching learning spaces and pedagogic change and drawing on data from interviews conducted with senior leaders, teachers and students in schools with flexible learning spaces, we report on pedagogic change as envisioned for, and enacted and experienced in, these spaces. It was found that there is no causal link between learning spaces and pedagogic change. Rather, pedagogic change is encompassed within multiple sets of relations and multiple forms of practice. We see promise for the emerging field of learning spaces in thinking about space from a relational, sociomaterial perspective. This approach pursues a non-dualist analysis of the space-pedagogy relation and offers less deterministic causal accounts of change than those that are commonly made in the popular and policy literatures.
\end{abstract}

Keywords: learning spaces; pedagogic change; sociomaterial approach; actor-network theory

\section{Introduction}

The collective title of 'learning spaces' is used to describe an emerging and complex field situated at the confluence of a number of disciplines, including education (Boddington and Boys 2011, xi). The significant public investment that has been made in many countries over the past decade in the educational infrastructure of universities, colleges and schools has prompted interest in the re-consideration of learning and the spaces where learning takes place. Attention is being given to the idea that arrangements of space critically influence patterns of learning and teaching in education (Li et al. 2005). Space has come to matter in policy processes that aspire to meet the needs of learners in the twenty-first century (Ministerial Council

*Corresponding author. Email: monicadm@unimelb.edu.au 
on Education Employment Training and Youth Affairs 2008; OECD 2013) and in educational practice (Brooks 2011, 2012). Indeed, space is thought to be a change agent. As the Joint Information Systems Committee (2006, 30) has it, 'spaces are themselves agents for change. Changed spaces will change practice'. How this change takes effect, however, remains an open question. Little educational research exists on what are often called flexible, innovative or new generation learning spaces. As Boddington and Boys (2011, xix) claim, 'learning spaces is a deeply complex and as yet under-researched field' and, we add, a field that is under-theorised.

In this article, we report on findings from a piece of empirical research which aimed to investigate the nature of the pedagogic practices undertaken in contemporary learning spaces in Victorian government schools. ${ }^{1}$ Sitting under the broad umbrella of twenty-first century learning, ideas such as collaborative, personalised and self-directed learning ${ }^{2}$ now drive the infrastructural arrangements for school education in Victoria and some other parts of Australia. As Newton and Gan (2012) have it,

during the past decade innovative school design has focused on studentcentred learning within rich digital learning environments. Many schools are shifting from the 'cells and bells' environment of classroom teaching into larger, more fluid spaces with a range of furniture settings. Rather than having one subject-specific teacher in an individual classroom, increasingly students work in a way that brings together learning across disciplines supported by teams of teachers.

The empirical research involved the collection of video case data in four schools in the state of Victoria and conduct of interviews with school leaders, teachers and students in these schools towards providing a range of perspectives on the nature of the pedagogic practices afforded in innovative learning environments (OECD 2013) and how each school's desired pedagogies are playing out in these environments. Deploying understandings of space which have been developed in cultural geography (Massey 2004, 2005; Murdoch 2006; Whatmore 2002) and actor-network theory (ANT) (Latour 2005; Law 2009; Murdoch 1998), we trace the sociomaterial (Fenwick, Edwards, and Sawchuk 2011) as manifested in the interview data. ${ }^{3}$ Each of these 'toolkits' is avowedly relationalist (Murdoch 1998, 369); both cultural geography and ANT challenge the idea of space as fixed and absolute in its co-ordinates, viewing it instead as 'open, multiple and relational, unfinished and always becoming' (Massey 2005, 59). We see promise for the emerging field of learning spaces in thinking about space from a relational, sociomaterial perspective. This approach pursues a nondualist analysis of the space-pedagogy relation and offers less deterministic causal accounts of change than those frequently put forward in the popular and policy literature (see for example, Oblinger 2006). 


\section{Background and context: Australia's Building the Education Revolution programme}

Constructing built environments that respond to student needs through the creation of new learning spaces 'has become government policy in England, Australia, Portugal, Finland and the Netherlands, amongst other nation states' (Loughlin 2013, 536). The Building the Education Revolution (BER) programme was a $\$ 16.2$ billion capital building programme initiated by the Australian Federal Government in response to the global financial crisis and included an economic stimulus package of construction and refurbishment of schools. A major policy initiative, it saw funding distributed through State Governments to schools in order to develop new learning spaces and facilities (Loughlin 2013). While the BER's primary goal was to support the economy, in the Victorian context, it was utilised to provide government schools with twenty-first century learning spaces for current and future students. Hybrid designs were developed which could accommodate traditional classroom-based approaches to teaching and learning as well as approaches such as team teaching and inquiry learning, which the new learning spaces are deemed well suited to support. This policy initiative can be understood as an exemplification of 'exhortative/developmental policies' (Ball et al. 2011), a category of policy which rather than demanding compliance 'can enable an active policy subject ... who is required to bring judgement, originality and "passion" ... to bear upon the policy process' (ibid., 615).

\section{Perspectives on learning spaces and pedagogic change: realist and relationalist}

Educational discourses of learning space are commonly set within an epistemology that takes it that meaning and matter belong to different categories and thus are different kinds of things (Law 2011). We call upon two disparate styles of reasoning, termed here 'realist' and 'relationalist', towards arguing that while a realist framing dominates discourse in the educational literature on learning spaces, learning spaces can, with profit, be thought of relationally.

A realist perspective: "We shape our buildings; therefore they shape us' ${ }^{4}$

Realist reasoning regarding learning spaces and educational change takes its point of departure from entities (e.g. built environment, design features, learning outcomes), rather than relations (e.g. socio-spatiality). This style of reasoning tends to play out in policy discourse on educational innovation and reform, for example, 'Different spaces are required for effective learning in the twenty-first century' (Ministerial Council on Education Employment Training and Youth Affairs 2008, 7); 'In a learning centred school, the built environment frames the provision of space for learning and teaching, collaboration and delivery of specialised services. It is conducive to quality 
learning outcomes' (Catholic Education Office Melbourne 2009, 2); and 'The design of new learning environments should enable teachers to work together differently, to learn and practise new skills together, and to readily access resources to support the teaching and learning relationship' (Department of Education and Early Childhood Development 2009, 1). A clear 'cut' is made between the physical world of 'new learning environments' and the human world of teachers' work practices, with the former world being perceived to have the potential to effect change to teachers' practice. As part of this framing, space and its uses are taken to be different aspects that reflect each other. This 'two-worlds' binary framing is similarly evident in findings from empirical research conducted with Principals of Victorian government schools:

In general, Principals revealed that they were planning to use the new centres as sites of change that could spread new approaches to teaching and learning through their schools, mirroring system priorities. Many believed that the openness and flexibility of the spaces would lead to greater interaction between teachers, team teaching and more professional learning. For some, the ICT would allow connection with other schools to provide more curriculum choices and learning activities. Principals expressed hope that they could achieve a sense of collective responsibility among teachers for all students, and independent learning skills in students, teachers using data to diagnose and plan differentiated curriculum, changes in behaviour management, and networking with other schools. (Hartnell-Young and Vacirca 2012, 1)

The modernist idea that building design (here, flexible, open plan) should reflect its contents ('new approaches to teaching and learning') underscores these findings. As does the idea that space is, or can be used as, a device for changing behaviours and practices. Dominant instrumental and behavioural understandings are effectively instantiated in a realist style of reasoning. In a realist world view, space has an essence; it can be designed as open, flexible and innovative, qualities which, when harnessed by those within it, can develop 'capacities in students for the twenty-first century'. Alternatively, it can be designed as bounded or contained; as coinciding with 'the egg-crate model that has been extant since the industrial revolution' and through which, presumably, these capacities are not developed (Fisher 2007, 55; Fisher and Newton 2014). A causal logic is implied; space and its occupation/occupants are directly related.

This realist world view is also evident in the empirical research on learning spaces, understandably so given that space is defined as physical space. Thus, in a recent study of newly established school libraries in the Australian state of Queensland, most of which were established with funding from the BER programme, it was found that 'the newly designed physical spaces had a direct impact on the patterns of participation and learning within the school' (Willis et al. 2013, 4). Reports of research 
conducted in Canada and Portugal, respectively, state that 'Learning takes concrete shape ... within its social-material surround. A school site should therefore support dynamic learning processes' (Gislason 2007, 6); and 'In an analysis of school renovation processes, it is essential to evaluate, on the one hand, the changes in educational practices, including the changing characteristics, roles and attitudes of the social actors directly and indirectly involved, and on the other, the mechanisms of appropriation of the space by these actors' (Marques, Veloso, and Sebastiao 2013, 62). Additionally, in a recent research report from the UK, it is claimed that school leaders in a new school building under construction sought to facilitate pedagogic change 'by flexible use of bigger spaces and teams of teachers' (Woolner et al. 2014, 49). And, in a study conducted in three Catholic primary schools in Australia, the impact of 'the introduction of open-plan, non-traditional learning spaces' was focused up (Saltmarsh et al. 2015, 317). In all instances above, space is taken to be given in advance and appropriated or used by social actors. It is not taken to come into existence or 'become' with these actors.

A relationalist perspective: It is 'about encounters between space and its occupation' (Boys 2011, 51, original emphasis).

Shifting the interpretive frame, in a relationalist perspective on learning spaces and educational change, (physical) space and (social) change are understood to be generated together. Here, space is not taken to be given in advance of practice. Temporal relations shift. Accordingly, space and its uses (effecting change) are no longer 'different aspects that reflect each other - as the binary oppositions model assumes - but are inseparable and interlocked, dynamically informing and influencing each other' (Boys 2011, 50-51). As widely acknowledged by social and cultural theorists such as Massey (1992, 2005), Soja (1989) and Thrift (2003, 2008), the spatial is socially constituted and space and time are conjoined.

Thus, it is shown that space can no longer be seen as a 'container' of heterogeneous processes; rather, space is now thought to be something that is (only provisionally) stabilised out of such turbulent processes, that is, it is made by heterogeneous relations. (Murdoch 2006, 4, original emphasis)

Or, as Thrift $(2003,96)$ has it, rather than being 'viewed as a container within which the world proceeds, space is seen as a co-product of those proceedings'. Thus, the spatial and the social need to be conceptualised together as is increasingly acknowledged in education (Boys 2011; Gulson 2007, 2011; Leander, Phillips, and Taylor 2010), albeit not commonly, as yet, in the literature on learning spaces. ANT is, par excellence, relationalist: 'space and time come about as consequences of the ways in which particular heterogeneous elements are related to one another' (Hubbard and Kitchin 2011, 273). And, with respect to these elements, particular importance is 
given to physical matter: material practices and the 'missing masses' (Latour 1992).

According to Boys $(2011,62)$, 'most of the current debate around innovative forms of learning spaces is still being articulated through older modernist ideas and assumptions about how architecture works, which believe that design can provide a direct fit between space and occupation, and can be designed as a functional and representational response to human behaviour'. The UK Building Schools for the Future programme, now discontinued, was formulated in these terms:

The design of these schools will shape the ways in which we think about, experience and conduct education in this country for the next 50-100 years. The educational visions upon which they are built will be solidified in bricks and mortar, the learning relationships they envisage will be captured in concrete and glass. The institutions created now will physically encapsulate and determine the ideas it is possible to have about education, learning and learning relationships until the dawn of the next century. (Rudd et al. 2006, 1)

Contrary to this modernist view, in a relationalist way of thinking, learning spaces and the uses made of these spaces are created and sustained together; they are in a mutually constitutive relationship. Design can never provide a direct fit between space and occupation, and this space is never simply occupied by people.

The concept of a learning space and the analytic focus shift considerably here. The character of the learning space changes with changes in its practice. As Gulson and Symes (2007, 102, original emphasis) have it, when commenting on the spatial turn taken in the latter part of the twentieth century in the social sciences, space is transient and social in nature: 'space is a construct not a given, is relative not absolute'. Educational spaces are 'fluid and ephemeral' (ibid., 105). They are in relation, constituted in textual, temporal and pedagogic processes, offering a perspective that has the potential to generate fresh understandings of learning spaces and pedagogic change and to challenge the means-ends impulses of realist reasoning about each of these. Little empirical research exists within the emerging field of learning spaces with regard to this perspective (see for exceptions, McGregor 2003, 2004; Mulcahy 2015). In fact, 'there is little known about the experiences of teachers and learners in newly designed learning spaces, and whether the potential for reimagined pedagogies is being realised' (Willis et al. 2013), altogether.

Learning spaces are no longer a 'container' for human activities, a product (architectural design, a built space) which can be appropriated by their teacher and student users and that can impact on learning outcomes. Spatiality is primarily to be seen not in terms of a backdrop against which action takes place, but in terms of activity or practice. Space is made (Smyth and McInerney 2013) or better, 'done' - constituted through action (Mulcahy 2006); 
subtended by 'relational thinking' (Massey 1999). As Massey explains, 'Thinking relationally is, in part, an attempt to reimagine the either/or constructions of binary thinking (where the only relations are negative ones of exclusion) and to recognise the important elements of interconnection which go into the construction of any identity' (1999, 12). In policy discourses and much of the academic literature on learning spaces, the either/or constructions of open/closed space, flexible/fixed space, innovative/traditional learning environments predominate. A politics attaches to these constructions such that the first named term and practice is privileged. Challenging this politics, a relational approach to space stresses a nonhierarchical way of thinking about difference. It opens learning spaces up to 'dynamic and complex processes of change' (Murdoch 2006, 3-4). Space does not exist prior to people or objects and their relations and does not take a singular and fixed form. Rather 'it is a product of relations-between, relations which are necessarily embedded material practices which have to be carried out' (Massey 2005, 9).

\section{A methodological note: tracing the sociomaterial}

ANT has been described as 'a sensibility to the messy practices of relationality and materiality of the world' (Law 2009, 142) and sits well with Massey's conceptualisation of space as 'a product of relations-between'. 'ANT reflexively provides a theory of interconnectedness through which to re-imagine educational practices as spatialised knowledge-building practices' (Edwards and Clarke 2002, 157). Here, it is assumed that if the actors gathered together in one space or setting (e.g. traditional classroom) are different to those gathered together in another (e.g. open learning space), different kinds of effects will be produced. These effects can take in identity (teacher and learner subjectivity), pedagogy (does pedagogic practice change in the shift from one learning space to another?) and politics (do power relations between teachers and students shift in the move from one learning space to another?). Needless to say, space does not have agency per se. It is an effect of particular relations, made by these relations; in ANT terms, it is a sociomaterial enterprise of network making.

Our thinking about learning spaces is organised through the categories of a typology first put forward by the sociologists of scientific knowledge Shapin and Schaffer (1985) in a historical study describing the origins of experimental science. Proposing the categories of sociality, textuality and materiality as the means of scientific knowledge making, these categories equally afford understandings of learning (defined minimally as growth in knowledge) and the pedagogic practice that produces it. We propose that pedagogic practice, including change to this practice, is variously social, textual and material. Socialities, textualities and materialities are micro-sites of knowledge making. Attending to these micro-sites induces an 
attentiveness to things, their agency and, indeed, their vibrancy (Bennett 2010). These three micro-sites are not distinct; their workings depend on one another. Socialities point to social arrangements and institutions, the categories of usual sociological interest, as well as social interactions and processes such as belonging and achieving a sense of place in the new learning spaces. Textualities recognise the role of discourses such as policy discourses of open, flexible learning spaces (Department of Education and Early Childhood Development 2009, 2011) and innovative learning environments (OECD 2013) and attend to meaning rather than physical matter. Lastly, materialities recognise the involvement of concrete physical practices in knowledge production. Thus, pedagogic change is an effect performed through material objects such as texts, technologies, artefacts, architectures and bodies and materialising processes (e.g. embodied encounters, space and place). In tracing the sociomaterial, it is assumed from the outset that learning and knowledge do not reside in individuals; they circulate in relationships, which can coalesce - form seemingly fixed points and foundations (e.g. open learning, traditional teaching).

\section{Data and methods}

The project being reported here was a small-scale, one-year study (2012-2013) sponsored by the authors' University in collaboration with the Victorian Department of Education and Early Childhood Development, which is committed to research on learning space design and its 'real-world' practice. Utilising a stratified sampling strategy, data were collected from school leaders, teachers and students located in (i) a large, suburban, government secondary school in a high socio-economic area; (ii) a large, outer suburban, government secondary school in a low socio-economic area; (iii) a medium size, government primary school in a relatively affluent suburb of a regional Victorian city; and (iv) a medium size, outer suburban government primary school servicing a low socio-economic and immigrant community. All schools sampled have a reputation for innovative pedagogic practice with regard to the 'take-up' of new learning spaces. Video-based case studies of 'naturally' occurring interactions in learning units at these schools were conducted and accompanied by interviews undertaken with school principals and assistant principals (seven altogether), participating teachers (nine altogether) and participating students (eight altogether). We report here on the interview data only. Analyses of these data were undertaken using the methodological approach of tracing the socio-material (Fenwick, Edwards, and Sawchuk 2011; Mulcahy 2013); thus, the meanings made in the interviews in each data set (school leader, teacher and student data sets) were grouped using the broad categories of sociality, textuality and materiality and patterns that formed in the data around how space and change connect (or not) were identified. Thus, in the student data set, meanings with regard to learning 
spaces tended to be oriented towards materialities of movement and pedagogy - the bodily capacity to 'wander around and learn with other people' and 'find little nooks and crannies' in which to learn. All interviews were conducted by the authors. Attention is given to the school leader data set, the teacher data set and the student data set and the respective practices of envisioning, enacting and experiencing pedagogic change. Distinctions drawn among these categories are analytical only; the entities to which they refer, for example bodies, spaces, places and discourses necessarily entail each other in practice (Orlikowski and Scott 2008). While treated as made by different relations and as mobilising different change networks, these categories overlap, both in spatial and in pedagogic terms.

\section{Learning spaces and pedagogic change: envisioning, enacting, experiencing}

Envisioning: 'Our buildings are so strategic to the vision'

School principals and their assistants attest to using newly built spaces as a 'catalyst for change'. As a secondary school principal has it, effecting change in schools 'comes back to what is the Vision and Value? What is important, and what does effective learning look like?' School leaders are involved everyday in what we will call naming and framing which may account for the tendency in the leader data set towards textual relations broadly, work of a meaning-making kind. Further to this practice, material practice also features strongly. Thus, a primary school principal declares that: 'to just say to teachers, well let's move into this space, do what you've always done and then we'll work it out from there, is just a lost opportunity for me', implying the significance of relations other than 'just say'. A secondary school principal, further to the one quoted above, speaks explicitly to the change agenda in her school:

I knew when I applied for the position (of Principal) that it was a school that was needing reform ... you then have the opportunity with a building like this ... so that's what I looked for straight away - what can I use as the crowbar? ... And certainly the experience I had at (my previous school) was just so powerful in doing this work because the lever there was very clear - it was about three schools coming together; it was about a socioeconomic profile that was dependent upon the agency of education to lift kids out of poverty. All of those sorts of powerful levers, but those ones wouldn't have worked here because it's an entirely different context, so I was glad that I had that. If I hadn't had that opportunity with that building, I think I would have ... I would have found something to use, I would have found a mechanism for inviting the conversation about how do we make a difference? But it wouldn't have been so clear, strong.

Change leadership, it appears, is a matter of words and actions: 'inviting the conversation about how do we make a difference' and using material 
objects ('that building') to leverage change. Meaning-making and matter-ing (Law 2004) both count. In an ANT rendering of these data, the change network that is coming into effect is composed of heterogeneous elements: a school in need of reform, a principal's prior experience of reform, a building providing the prospect of reform, and mechanisms for leveraging it. These mechanisms are both semiotic and material.

A clear thread in the leader data concerns the idea that principles for teaching and learning need to drive any arrangements made regarding new learning environments. As the principal above comments, 'of course the first step is, well what do we want for teaching and learning?' Pedagogic considerations predominate and spatial arrangements subserve educational purposes and goals. The principal above continues: 'staff were required to ask themselves: 'Well, what is a learning space? What does a learning space offer - not, what does it look like, but what does it offer or provide that's going to deliver for kids?' She elaborates: '... (T)he connection between what the curriculum and pedagogical imperatives were for the learning had to drive who was in the space ... whose learning was going to benefit from the kind of environment that was on offer'. Reflecting policy discourses with regard to pedagogy and learning spaces (Department of Education and Early Childhood Development 2011; Ministerial Council on Education Employment Training and Youth Affairs 2008), envisioning spaces for learning involves expecting to see "collaboration, ... monitoring of growth for learning, ... teachers negotiating with students and students negotiating with each other around the curriculum'.

New school buildings matter, not as discrete objects with properties of openness and flexibility, but as effects of materialising processes in which school personnel and objects take part. The building gives the principal above 'licence ... to ask those bigger questions' and to 'crowbar' the process of curriculum and pedagogic change. The secondary school principal referred to in the opening of this section states: 'Our buildings are so strategic to the vision ('the collaborative learning model'), because the House (a mini-school within the larger school) is not just a space, it's also a structure - it's a learning model'. Here, meaning-making ('the vision') and matter-ing ('our buildings') are conjoined; together they work to bring the change network into being.

Boundaries between the human world and the physical world become increasingly blurry. A primary school principal tells a small 'space story':

I'm in the process of building a shared teacher office because at the moment the teachers have dragged their desks out and put them in the corridor, ... so they can team across to home spaces and have that shared camaraderie. So, I'm putting in an office so that they can get all their eight desks in the one office and go to their separate pods but still have that connectedness through the shared office. 
Here, pedagogic change assumes the form of 'team(ing) across to home spaces'. It is an embodied (corporeal, material) process of dragging desks out and putting them in the corridor towards the teaching staff 'hav(ing) that connectedness' and 'gett(ing) found space for interactive learning'. We posit that pedagogic change and spatial change come into being together; they are in relation. The principal summarises the situation thus: 'We've been able to make sure there's close connectedness. No doors, because unfortunately doors close'. Learning space is not fixed and absolute in its co-ordinates. It is 'open, multiple and relational, unfinished and always becoming' (Massey 2005, 59). It is a practice or process - here, of not allowing doors - that is enacted in parallel with, or tangled up in (Nespor 1997), the process of pedagogic change. A more contingent understanding of space-pedagogy relations emerges in these data than the realist and rationalist perspective of, as it were, first get the design right and all else should follow.

Enacting: 'Teachers have had to adapt. Some have done it better than others'

Like school leaders, school teachers are caught up in the sociomaterial enterprise of change, but here change is of a more confined kind. Teachers are expected to enact envisioned change with the change enterprise appearing far more uncertain for them than for school leaders. Teachers are positioned differently with respect to the change networks that are being built in their schools; they have not necessarily had a hand in setting the change agenda or in determining aspects of the learning spaces in which they are being asked to teach. In contrast with school leaders, they might be considered to be more networktakers than network-makers. Thus, the process of developing new learning environments challenged teachers' conceptions of their professional roles and identities. Their active engagement with the policies of 'innovative learning spaces' and 'twenty-first century learning', as communicated to them by the state education system and school leaders, asked them to step back from 'comfortable' prior practices and explore mostly unfamiliar educational theories, visions and practices. A primary school teacher outlines this challenge thus:

The most challenging part is that before being a teacher you've got these visions of how you want your class set up and how you want to run it, and what rules you're probably going to enforce, and coming into a team environment and working with the kids, it's not just about me teaching, but about what the other advisers [teachers] want, and what the kids want as well.

And another primary school teacher discusses her changing mindset as follows:

Because it was all very flexible, I kind of had to change my mindset and be really open to what we were doing here, and every time I just kept thinking 
'this is ... this is not for me, this is not for me', but just with that support, and I think the team as well, has kind of really helped.

Social relations (rather than textual/representational relations) tend to subtend the pedagogic change networks that are in place. In developing new professional identities and mindsets, teachers talked about their growing 'confidence' and 'comfort' working closely with colleagues in contemporary spaces and many identified benefits linked with pedagogical approaches supported by collaborative social structures such as teaching teams. Yet, their relative welcoming of change differed and, we infer, influenced the kind of change networks that came into effect. Some networks were more robust than others. An experienced secondary school teacher implied that generational relations were of importance in network making. He suggested that while younger teachers were 'pretty keen to be flexible ... some of the older of us are sort of counting off how many more terms we've got and probably not wanting to change too much'.

With a greater sense of enthusiasm, an early career primary school teacher describes her engagement with new educational settings in these terms:

I love it here with the big open spaces. It's fantastic, it really is. It's just easier, I don't know, to work together as a team and plan together and do our focus groups. I think now because [we] have joined together, I think that it's worked really well, really well.

This 'successful' change network is underwritten by social interactions and processes: working together as a team and planning together. 'Sociality' appears to be the glue that holds this network together. The same primary school teacher went further to celebrate the opportunities afforded by new spaces: 'It's just made the people more collegiate I think. Because the walls are open, you see what others are doing, you can bounce off each other, and it just promotes that sense of community'. In contrast, a secondary teacher reports:

I think that at the start of the year we flounder, all of us flounder a little bit because we're trying to get to know our students, and I think it [the spaces] mitigates against that a little bit ... the notion of the teacher knowing the students, the students feeling comfortable with the teacher, and I think that we struggle with developing those close ties, and you're trying very hard to do that in first term, but once you have established some sort of link with the students, then I think you feel more comfortable.

Another secondary teacher, who self-describes as embracing the new learning spaces 'to a certain extent', comments thus:

Teachers have had to adapt. Some have done it better than others, to be honest. Changes in approaches [means] that there's a lot more group work, a lot 
more student sort of centred stuff. ... the furniture doesn't really lend itself to 75 min of teacher-led stuff, most of the time. So there's a lot of things like kind of ... student-centred stuff - brainstorming groups. ... So there's probably a lot less direct instruction, more independent work. ... It's great for independent learners, but not everybody is at this stage independent.

Significant pedagogic issues are raised here and relate to other reported experiences and previous research (Saltmarsh et al. 2015; Woolner et al. 2014). In comparison with the patterns that formed in the school leader and student data sets, there is greater variability in the responses made by teachers to using new designs of learning environments and effecting change. The networks of pedagogic change that grow up are contingent upon the cultures of practice that typify teaching in different school sectors with their particular curricula and pedagogic parameters and constraints (e.g. in secondary schools, achieving a flexible timetable).

Experiencing: 'You can be where you need to be and learning what you need to be learning'

Generally, the student data reflect a preference for learning in new environments over 'classroom-as-container' and reveal how the students have adapted to changed pedagogic practices and different ways of using spaces. Positives include increased mobility in more open spaces, more individualised learning, more access to teachers (or teams of teachers as noted in the two primary schools), and improved ability to make new friends across the learning community for collaborative learning and for socialising with other students. The change networks that form are made largely exclusively by social and material relations; mobile pedagogies and experiential learning (arguably more social than academic) come to the fore.

A Secondary school student described the new learning centre as "pretty much one classroom with a whole bunch of different classes going on at the same time. It works well, it's like a flow of work', while in another Secondary school, it was 'interesting because everything is so open, instead of like hallways and classrooms, and we can experience like everything ... We can wander around and learn with other people, so it's good'. In both primary schools, the students valued 'the ability to roam and having a lot of room to work with'. 'It's good because you can work with other classes. ... It's not too enclosed so you can work with the whole pod, and you can go down the other end and work with the whole unit' (in this case, seven classes). All data reflected the students' appreciation of getting to know their learning community or cohort, with examples of how this affected their learning. 'You get to know everyone in your community and you have your friends that you can trust in the community' and 'they can help you out sometimes if you have troubles'. Additionally, you are 'more interactive with others and you can share learning more in groups [and] get to know more friends and extend your choice of learning partners'. 
According to a secondary student, 'it's more of a communal sense rather than if you're in individual classrooms with your class'. She liked the whole year level being together (with their centrally placed lockers) in the learning centre because in always being together 'they've become a lot closer ... and ... it's really nice to be together. Yeah, even though, like also you can see everyone, like they're just there - you don't have to be talking to them. It's just nice to see them there, but you can still concentrate and be in small groups'. The 'togetherness', connectedness or 'presence' (Sørensen 2013) fosters a sense of belonging and group identity. Bissell $(2010,272)$ writes of the non-verbal development of affective atmosphere which is perceived and sensed through the body and forms part of 'the ubiquitous backdrop' which is forceful and affects the ways in which spaces are inhabited. Another secondary student explains how he is affected by the atmosphere or the potential in place (Duff 2010, 891, original emphasis).

I actually find it a lot easier to work, because the environment changes your emotion. It sounds kind of cheesy, but it changes the way that you look at the work. I mean if you can sit in a comfortable position in a place that you want to sit, rather than in a classroom where you can't leave and there's somebody sitting three seats down who's really distracting, and you can't move ... [it is] easier to concentrate on the work, but it is also your decision [as a student] ... I need to get this work done, I need to move away from the distractions. And you can also make the choice that I don't want to do the work, I can sit next to the distraction (added emphasis).

Similarly other students liked 'the openness because it is a lot easier to work' and the fluidity of spaces afforded access to collaborative learning (or not). 'You can go to other people, ask for help from other people, work together, and other times you just don't want anyone else, you just want to sit on your own'.

Such atmospheres are a complicated assemblage of social, material, and affective components, linked together in the sinews of practice, in the materiality of place and finally in the emergent 'co-presencing' of bodies, place, and self. (Duff 2010, 891).

A secondary student from the school in which the principal was given 'licence ... to ask those bigger questions' and to 'crowbar' change describes how he learns in spaces afforded by the open flexible learning centre:

At the start of the class you get sent to a specific area, but that's just to mark the roll. But in some classes we can go off and disburse into the centre, and we can take a spot or an area where we feel that we would learn the best quieter, louder, more crowded, less crowded. ... It also allows you to work at your own level, especially in classes like maths, a lot of the students are at different levels, and they can split up into different groups and work together, and that helps us a lot ... I learn the best when I'm up against the whiteboard 
with the teacher, getting almost tutored, and that's more available to me when there's a portable whiteboard maybe around the corner or something, and I can just call a teacher and say, 'hey, I need help with this, can you come help me?' And he'll be like, 'yep, sure', rather than having a whiteboard in the front of a classroom where everybody's seeing it ... [it's] more specific to you as a person than it is to your class.

Clearly, this student's learning is a sociomaterial affair; it's made through 'getting almost tutored' by the teacher in association with 'a portable whiteboard maybe around the corner', rather than 'in the front of a classroom where everybody's seeing it'. It is line with the findings of recent empirical research on pedagogic practices in open-plan learning environments: 'textiles such as soft rugs on floors and comfortable upholstered seating created inviting, more intimate spaces demarcated for quiet activities such as reading' (Saltmarsh et al. 2015, 7).

Secondary students highlight the ephemeral nature of learning spaces and how the character of learning space changes with changes in its practice/practitioners. 'In some subjects the teachers won't really mind if you wander around, but other subjects, like, you need to work harder ... and stay in one place'. But 'some teachers like ... see the people who wander around, they actually sometimes get more done because they're having fun ... and can work with other kids ... so that's good too'. Here, the students articulate the difference between the traditional discourse and practice of learning spaces -'work hard(er)' and 'stay in one place' - and the 'multilocational and processual experience' (Fendler 2013, 787) of these spaces as lived by students. There is a strong sense in the student data set that learning 'does not simply take place in space, but rather is produced with space; as an interactive, connected field' (Hickey-Moody and Malins 2007, 10, original emphasis).

\section{The mutual becoming of space, pedagogy and change}

The process of effecting pedagogic change 'in' contemporary learning environments is a relational achievement drawing on diverse social, discursive and material resources, including physical learning spaces. A realist rendering of the data in which it is assumed that learning space is given in advance of practice and functions as a clear agent for change (Joint Information Systems Committee 2006) can provide much needed information about the impacts of newly designed learning spaces on learning and related pedagogic processes, however, significant occlusions occur in such a rendering. While human meaning-making - interaction and discourse - is attended to, the materiality of pedagogy (Ellsworth 2005) and the material dimensions of education (Kalthoff and Roehl 2011; Roehl 2012) slip from view. The data demonstrate that material objects such as newly designed physical spaces are neither just there waiting to be occupied or used, 
'nor do they leave school lessons and the knowledge constituted therein unchanged' (Roehl 2012, 109). Rather, they exert force and exercise agency well illustrated in the case of the secondary student who learns the best when he is

up against the whiteboard with the teacher, getting almost tutored, and that's more available to me when there's a portable whiteboard maybe around the corner or something, and I can just call a teacher and say, 'hey, I need help with this, can you come help me?'

There is a sense here that the way to create conditions for learning to emerge in learning spaces is for teachers to turn to material objects in full knowledge of the pedagogic possibilities that they open up. Learning 'the best', effecting growth in knowledge, is a socio-material matter, a matter of mutual social and material encounter. As Duff $(2013,195)$ has it, '(I)f encounters in and with the world force us to think, then learning should be understood as the outcome of those encounters which enable a body to expand or increase the array of bodies, objects and entities it may affect and be affected by'.

Encounters 'in and with the world' are also not neutral or benign. They can shift the balance of power between student and teacher - 'hey, I need help with this, can you come help me?' - or serve to strengthen customary school leader and staff relations. Thus, school leaders strive to head off specific encounters by students and staff with key material actors - doors and operable walls. A primary and a secondary school principal, respectively, report: 'we've been able to make sure there's close connectedness. No doors because unfortunately doors close' and

And so one of the things I had to do and I constantly have to do is challenge them (teachers), and challenge it in a really direct way, which is simply go in and say - 'the wall is closed, why is the wall closed?'

For school principals, effecting pedagogic change is a very specific political-material practice and a practice that requires ongoing work. In a realist rendering of the change process, this work is kept from view. This rendering is ultimately reductionist. Politics plays out in material practice.

The empirical material implies an expanded understanding of what is generally inferred by the term learning space and provides for a more 'inclusive' form of learning space discourse. We argue that much of the existing empirical research on learning spaces is limiting when it comes to an appreciation of the complexity of relations between learning space design and use, and between learning spaces and pedagogy. Thinking the term learning spaces as verb rather than noun, that is, as something we do (a matter of encounter), rather than something we have (a new learning environment, a finished design) affords acknowledgement of the multiplicity 
and mutability of spatial and pedagogic practices, as reflected in the interview data. For teachers in primary schools, the new learning spaces are spaces in which they can 'work together as a team and plan together'. They are 'just easier'. For teachers in secondary schools, difficulties can develop: 'I think that at the start of the year we flounder'; 'the whole place is like a fishbowl, you know there's glass everywhere'. Policy discourses of openness and innovation are not necessarily shared by practitioners.

What counts as a learning space? In the final analysis, a range of dynamics comes into play, discursive, material and social. A learning space is the product of heterogeneous relations: (i) a vision or a discursive dynamic such as twenty-first century learning, student-centred learning or personalised learning; (ii) a design or a material dynamic such as a traditional classroom or a newly built open space or a mix of each; and (iii) a shared structure or a social dynamic such as the organisational set up of the school: 'the House is not just a space, it's also a structure - it's a learning model'. As an assistant principal has it, 'I don't think any building replicated, any (one) building really works in schools. I think you've got to think through what are the needs of the school, and be very clear about what you're looking for'. What we call a learning space is more than a physical building in which learning occurs. 'It is the product of interrelations and materially-embedded practices, connected in space and time to wider flows of ideas, technologies and discourses in society' (McGregor 2003, 368-369). Learning spaces have a certain plasticity; they are 're-written and re-inscribed, formed and deformed as each pedagogic moment is transformed into another and as they are acted out in time' (Gulson and Symes 2007, 105). As a school leader in a primary school comments: 'You never go into a space that's fixed for a number of weeks because the teachers will change those spaces according to the purposes of the learning'. The point is to acknowledge that a front-end model of learning spaces, where it is assumed that space is given in advance and that spaces specifically designed with processes of teaching and learning in mind will logically lead to changed practice, can be limiting when it comes to understanding specific encounters.

\section{Disclosure statement}

No potential conflict of interest was reported by the authors.

\section{Notes}

1. Victoria is a major state within Australia. Given Australia's federal political structure, responsibility for education lies with individual states.

2. Reference is also made in policy material to terms like constructivist learning, active learning, inquiry project-based learning and individualised learning each of which can be considered to also sit under this broad umbrella. 
3. Space does not permit an exploration of the observational or "naturally occurring' data. See however, Mulcahy (2015).

4. This observation (or a version of it) was made by Winston Churchill in a speech delivered in the House of Commons on 28 October 1944. Having sustained heavy bombing damage during the Battle of Britain, the House of Commons was being rebuilt.

\section{ORCID}

Dianne Mulcahy (D) http://orcid.org/0000-0002-1027-2152

\section{References}

Ball, S., M. Maguire, A. Braun, and K. Hoskins. 2011. "Policy Subjects and Policy Actors in Schools: Some Necessary but Insufficient Analyses." Discourse: Studies in the Cultural Politics of Education 32 (4): 611-624.

Bennett, J. 2010. Vibrant Matter: A Political Ecology of Things. Durham, NC: Duke University Press.

Bissell, D. 2010. "Passenger Mobilities: Affective Atmospheres and the Sociality of Public Transport." Environment and Planning D: Society and Space 28: 270-289.

Boddington, A., and J. Boys 2011. "Re-shaping Learning - An Introduction." In Re-shaping Learning: A Critical Reader, edited by A. Boddington and J. Boys, xi-xxii. Rotterdam: Sense.

Boys, J. 2011. "Where is the Theory?" In Re-shaping Learning: A Critical Reader, edited by A. Boddington and J. Boys, 49-66. Rotterdam: Sense.

Brooks, D. C. 2011. "Space Matters: The Impact of Formal Learning Environments on Student Learning." British Journal of Educational Technology 42 (5): 719-726. doi:10.1111/j.1467-8535.2010.01098.x.

Brooks, D. C. 2012. "Space and Consequences: The Impact of Different Formal Learning Spaces on Instructor and Student Behavior." Journal of Learning Spaces 1 (2). http://libjournal.uncg.edu/ojs/index.php/jls/article/view/285.

Catholic Education Office Melbourne. 2009. Learning Centred Schools: A Sacred Landscape. Melbourne: CEOM.

Department of Education and Early Childhood Development. 2009. Pedagogy and Space: Transforming Learning through Innovation. Melbourne: Department of Education and Early Childhood Development.

Department of Education and Early Childhood Development. 2011. Making the Most of Flexible Learning Spaces: A Guide for Principals and Teachers. Melbourne: Department of Education and Early Childhood Development.

Duff, C. 2010. "On the Role of Affect and Practice in the Production of Place." Environment and Planning D: Society and Space 28 (5): 881-895.

Duff, C. 2013. "Learning to Be Included." In Cartographies of Becoming in Education, edited by D. Masny, 193-207. Rotterdam: Sense.

Edwards, R., and J. Clarke. 2002. "Flexible Learning, Spatiality and Identity." Studies in Continuing Education 24 (2): 153-165.

Ellsworth, E. 2005. "The Materiality of Pedagogy: Sensations Crucial to Understandings." In Places of Learning: Media, Architecture, Pedagogy, 15-36. New York: RoutledgeFalmer.

Fendler, R. 2013. "Becoming-learner: Coordinates for Mapping the Space and Subject of Nomadic Pedagogy." Qualitative Inquiry 19 (10): 786-793. 
Fenwick, T., R. Edwards, and P. Sawchuk. 2011. Emerging Approaches to Educational Research: Tracing the Sociomaterial. London: Routledge.

Fisher, K. 2007. "Pedagogy and Architecture." Architecture Australia 96 (5): 55-57.

Fisher, K., and C. Newton. 2014. "Transforming the Twenty-first-century Campus to Enhance the Net-generation Student Learning Experience: Using Evidence-based Design to Determine What Works and Why in Virtual/Physical Teaching Spaces." Higher Education Research \& Development 33 (5): 903-920. doi:http://www.tandfonline.com/action/showCitFormats?doi=10.1080/ 07294360.2014 .890566$.

Gislason, N. 2007. "Placing Education: The School as Architectural Space." Paideusis 16 (3): 5-14.

Gulson, K. N. 2007. Spatial Theories of Education: Policy and Geography Matters. Hoboken, NJ: Taylor \& Francis.

Gulson, K. N. 2011. Education Policy, Space and the City: Markets and the (In) visibility of Race. New York: Routledge.

Gulson, K. N., and C. Symes. 2007. "Knowing One's Place: Space, Theory, Education." Critical Studies in Education 48 (1): 97-110.

Hartnell-Young, E., and E. Vacirca. 2012. "How Principals Accept the Gifts Embodied in New School Infrastructure and Appropriate Them to Their Change Agendas." Paper presented at the British Educational Research Association Annual Conference, University of Manchester. http://www.bera.ac.uk/bera2012/ pdf/BERA2012_0102.pdf.

Hickey-Moody, A., and P. Malins 2007. "Introduction: Gilles Deleuze and Four Movements in Social Thought." In Deleuzian Encounters: Studies in Contemporary Social Issues, edited by A. Hickey-Moody and P. Malins, 1-24. Basingstoke: Palgrave Macmillan.

Hubbard, P., and R. Kitchin, eds. 2011. Key Thinkers on Space and Place. London: Sage.

Joint Information Systems Committee. 2006. "Designing Space for Effective Learning: A Guide to 21 st Century Learning Space Design.” http://www.jisc.ac.uk/ uploaded_documents/JISClearningspaces.pdf.

Kalthoff, H., and T. Roehl. 2011. "Interobjectivity and Interactivity: Material Objects and Discourse in Class." Human Studies 34 (4): 451-469. doi:10.1007/ s10746-011-9204-y.

Latour, B. 1992. "Where Are the Missing Masses? The Sociology of a Few Mudane Artifacts." In Shaping Technology/Building Society: Studies in Sociotechnical Change, edited by W. E. Bijker and J. Law, 225-258. Cambridge, MA: MIT Press.

Latour, B. 2005. Reassembling the Social: An Introduction to Actor-Network-Theory. Oxford: Oxford University Press.

Law, J. 2004. "Matter-ing: Or How Might STS Contribute." http://heterogeneities. net/publications/Law2004Matter-ing.pdf.

Law, J. 2009. "Actor-network Theory and Material Semiotics." In The New Blackwell Companion to Social Theory. 3rd ed., edited by B. S. Turner, 141-158. Chichester: Wiley-Blackwell.

Law, J. 2011. "Heterogeneous Engineering and Tinkering." http://www.hetero geneities.net/publications/Law2011HeterogeneousEngineeringAndTinkering.pdf.

Leander, K. M., N. C. Phillips, and K. H. Taylor. 2010. "The Changing Social Spaces of Learning: Mapping New Mobilities." Review of Research in Education 34 (1): 329-394. 
Li, P. P., J. Locke, P. Nair, and A. Bunting. 2005. "Creating 21st Century Learning Environments." PEB Exchange, Programme on Educational Building, 2005/10 OECD. doi:10.1787/558676471016.

Loughlin, J. 2013. "How Photography as Field Notes Helps in Understanding the Building the Education Revolution." The Australian Educational Researcher 40 (5): 535-548. doi:10.1007/s13384-013-0112-1.

Marques, J., L. Veloso, and J. Sebastiao. 2013. "How to Rebuild a Secondary School: Space, Knowledge and Education." In The International Handbook of Cultures of Education Policy (Volume 1): Comparative International Issues in Policy-Outcome Relationships - Achievement with Family and Community Involvement, edited by B. Boufoy-Bastick, 59-101. Strasbourg: Analytrics.

Massey, D. 1992. "Politics and Space/Time." New Left Review I (196): 65-84.

Massey, D. 1999. "Issues and Debates." In Human Geography Today, edited by D. Massey, J. Allen, and P. Sarre, 3-21. Cambridge: Polity Press.

Massey, D. 2004. "The Political Challenge of Relational Space: Introduction to the Vega Symposium." Geografiska Annaler. Series B, Human Geography 86 (1): 3.

Massey, D. 2005. For Space. London: Sage.

McGregor, J. 2003. "Making Spaces: Teacher Workplace Topologies." Pedagogy, Culture \& Society 11 (3): 353-375.

McGregor, J. 2004. "Spatiality and the Place of the Material in Schools." Pedagogy, Culture \& Society 12 (3): 347-372.

Ministerial Council on Education Employment Training and Youth Affairs. 2008. Learning Spaces Framework: Learning in an Online World. Carlton South: MCEETYA.

Mulcahy, D. 2006. "The Salience of Space for Pedagogy and Identity in Teacher Education: Problem-based Learning as a Case in Point." Pedagogy, Culture and Society 14 (1): 55-69.

Mulcahy, Monica Dianne. 2013. "Turning around the Question of 'Transfer' in Education: Tracing the Sociomaterial." Educational Philosophy and Theory 45 (12): 1276-1289.

Mulcahy, D. 2015. "Re/assembling Spaces of Learning in Victorian Government Schools: Policy Enactments, Pedagogic Encounters and Micropolitics." Discourse: Studies in the Cultural Politics of Education 36 (4): 500-514.

Murdoch, J. 1998. "The Spaces of Actor-network Theory." Geoforum 29 (4): 357-374.

Murdoch, J. 2006. Post-structuralist Geography: A Guide to Relational Space. London: Sage.

Nespor, J. 1997. Tangled up in School: Politics, Space, Bodies, and Signs in the Educational Process. Mahwah, NJ: L. Erlbaum Associates.

Newton, C., and L. Gan. 2012. "Revolution or Missed Opportunity." Architecture Australia 101 (1): 74-78. http://architectureau.com/articles/revolution-or-missedopportunity/.

Oblinger, D. 2006. "Space as a Change Agent." In Learning Spaces, edited by D. Oblinger. Washington, DC: EDUCAUSE.

OECD. 2013. Innovative Learning Environments, Centre for Educational Research and Innovation. Paris: OECD.

Orlikowski, W. J., and S. V. Scott. 2008. "10 Sociomateriality: Challenging the Separation of Technology, Work and Organization." The Academy of Management Annals 2 (1): 433-474. 
Roehl, T. 2012. "Disassembling the Classroom - An Ethnographic Approach to the Materiality of Education." Ethnography and Education 7 (1): 109-126.

Rudd, T., C. Gifford, J. Morrison, and K. Facer. 2006. What If? Reimagining Learning Spaces. Futurelab.

Saltmarsh, S., A. Chapman, M. Campbell, and C. Drew. 2015. "Putting "Structure within the Space": Spatially Un/responsive Pedagogic Practices in Open-plan Learning Environments." Educational Review. 67(3) 315-327 doi:10.1080/ 00131911.2014.924482.

Shapin, S., and S. Schaffer. 1985. Leviathan and the Air-pump: Hobbes, Boyle, and the Experimental Life. Princeton, NJ: Princeton University Press.

Smyth, J., and P. McInerney. 2013. "Making 'Space': Young People Put at a Disadvantage Re-engaging with Learning." British Journal of Sociology of Education 34 (1): 39-55.

Soja, E. W. 1989. Postmodern Geographies: The Reassertion of Space in Critical Social Theory. London: Veso.

Sørensen, E. 2013. "Human Presence: Towards a Posthumanist Approach to Experience." Subjectivity 6 (1): 112-129.

Thrift, N. 2003. "Space: The Fundamental Stuff of Human Geography." In Key Concepts in Geography, edited by S. Holloway, S. Rice, and G. Valentine, 95-107. London: Sage.

Thrift, N. 2008. Non-representational Theory: Space, Politics, Affect. London: Routledge.

Whatmore, S. 2002. Hybrid Geographies: Natures, Cultures, Spaces. London: Sage.

Willis, J., D. Bland, H. Hughes, and R. Elliot-Burns. 2013. "Reimagining School Libraries: Emerging Teacher Pedagogic Practices." Paper presented at the Australian Association for Research in Education Annual International Conference Adelaide. http://www.aare.edu.au/publications-database.php/8415/reimagining-school-li braries-emerging-teacher-pedagogic-practices.

Woolner, P., J. Clark, K. Laing, U. Thomas, and L. Tiplady. 2014. "A School Tries to Change: How Leaders and Teachers Understand Changes to Space and Practices in a UK Secondary School.” Improving Schools 17 (2): 148-162. 